\title{
EFFECTS OF THYROTROPIC HORMONE ON CARBOHYDRATE METABOLISM IN THYROID SLICES *
}

\author{
By WILFRIED MERLEVEDE, GALEN WEAVER, $\dagger$ AND BERNARD R. LANDAU $\ddagger$
}

(From the Departments of Medicine and Biochemistry, Western Reserve University, Cleveland, Ohio)

(Submitted for publication July 12, 1962; accepted March 28, 1963)

The biochemical site where thyrotropic hormone (TSH) acts to initiate changes in metabolism remains uncertain. Field, Pastan, Johnson, and Herring (2) demonstrated a relatively immediate effect of TSH upon the oxidation of glucose hy a thyroid-slice system. TSH caused a greater increase in the oxidation to $\mathrm{CO}_{2}$ of carbon 1 than carbon 6 of glucose, and this was accompanied by an increase in triphosphopyridine nucleotide (3, 4). They suggested that a primary site of TSH action is at the nucleotide level and that changes in nucleotide concentrations result in an increase in glucose metabolism via the pentose cycle (PC).

The purpose of this report is to describe results of experiments with thyroid slices designed to determine: 1) the quantitative contribution of the $\mathrm{PC}$ to glucose metabolism in the absence and presence of $\mathrm{TSH} ; 2$ ) the effect of TSH on the conversion of glucose to glycogen; 3) the consequences of increasing the availability of exogenous glucose to the slice system; and 4) the effects of other hormones on the metabolism of glucose by the thyroid. The first two studies were performed because of the possibility that some hormones of pituitary origin may initiate an increase in nucleotide availability and PC metabolism by stimulating the glycogen degradative mechanism (5). The latter two studies were intended to establish

\footnotetext{
* Supported by grants from the American Heart Association, the National Institute of Arthritis and $\mathrm{Me}$ tabolic Diseases (A-4411), the Cleveland Diabetes Association, and the Fund for the Study of Diabetes Mellitus and Related Diseases of Western Reserve University. A portion of this work has been published in abstract form (1).

$\dagger$ Work performed in partial fulfillment of the requirements of the Project Teaching Program of the Medical Curriculum, Western Reserve University School of Medicine.

\$This study was performed during the tenure of an established investigatorship of the American Heart Association.
}

whether or not the pattern of glucose metabolism attributable to TSH could be reproduced under other well-defined conditions.

\section{METHODS AND MATERIALS}

Procedure. Incubation conditions were only slightly modified from those of Field and associates (2). Slices were prepared from beef thyroids obtained at the abattoir. The thyroids were removed from the steers immediately after exsanguination and before evisceration. They were chilled on ice during transport to the laboratory, and slicing was completed within 1 to 2 hours after the animals were killed. About $200 \mathrm{mg}$ of slices was placed in a bottle containing $2 \mathrm{ml}$ of Krebs-Ringer bicarbonate solution (6) with $\mathrm{C}^{\mathbf{1 4}}$-labeled glucose or fructose at a concentration of 1 or $10 \mathrm{mg}$ per $\mathrm{ml}$. A $1-\mathrm{ml}$ plastic cup was suspended above the solution by a wire inserted through a serum bottle-stopper. At the completion of the incubation, $0.2 \mathrm{ml}$ of $2 \mathrm{~N} \mathrm{NaOH}$ was added to the cup and $1 \mathrm{ml}$ of $2 \mathrm{~N} \mathrm{H}_{2} \mathrm{SO}_{4}$ to the medium by injection through the stopper. The bottles with contents were shaken for 30 minutes at $37^{\circ} \mathrm{C}$ to absorb the $\mathrm{C}^{14} \mathrm{O}_{2}$ into the alkali. The contents of the cups were then added to a $\mathrm{BaCl}_{2}$ solution, and the resulting $\mathrm{BaCO}_{3}$ precipitate was plated and assayed for $\mathrm{C}^{14}$ activity in a proportional gas-flow counter.

Incorporation of $\mathrm{C}^{\mathbf{1 4}}$ into glycogen of the slices was determined following $\mathrm{KOH}$ digestion (7). Nonradioactive glycogen was added as carrier to the digest, and precipitation was accomplished by ethanol addition. The glycogen was purified by repeat solution in water and precipitation with ethanol. It was then hydrolyzed in dilute sulfuric acid. In some experiments, osazones were prepared from the hydrolysates, plated, and assayed for $\mathrm{C}^{14}$ activity (8). In the majority of the experiments, samples of the glycogen hydrolysate were assayed in a liquid scintillation counter with dioxane containing naphthalene, 2,5-diphenyloxazole (PPO), and 1,4-bis-2(4methyl-5-phenyloxazoy1) benzene (dimethyl POPOP) as solvent (9). Results identical to those obtained with osazones have been demonstrated, and the method has proved more efficient in time as well as in counting. ${ }^{1}$

1 Ethanol addition to a $\mathrm{KOH}$ digest of thyroid yields a precipitate that after hydrolysis with acid contains considerable reducing substance as measured by the SomogyiNelson method (10) (mean of $84 \mu \mathrm{g}$ of glucose equiva- 
When glucose-2- $\mathrm{C}^{14}$ or fructose-2-C $\mathrm{C}^{\mathbf{1 4}}$ was the labeled substrate, the glycogen was isolated by precipitation with ethanol of a $\mathrm{KOH}$ digest, followed by extraction with trichloroacetic acid and repeat precipitations. It was hydrolyzed, and the resulting glucose was degraded with Leuconostoc mesenteroides (12), so that the activity in each of the six carbons of the glucose was determined. As a control, it was shown that glycogen isolated from slices added to the medium, but not incubated, contained no radioactivity. The specific activity of the labeled glucose or fructose added to the medium was assayed as barium carbonate following combustion by the method of Van Slyke and Folch (13).

Substrates. Glucose-1-C $C^{14}$ (lot 64-63) and $-6-C^{14}$ (lots 64-64 and 12-1-2037) were obtained commercially. ${ }^{2}$ On incubations of the Krebs-Ringer solution containing glucose-1- $\mathrm{C}^{14}$ in the absence of slices, radioactivity representing $0.07 \%$ of the added counts was assayed in the barium carbonate plate. This "carbonate-like" activity was present in the glucose added and not formed during incubation, since 1 ) as much radioactive "carbonate" was obtained on acidification of the solution without incubation as after 2 hours of incubation, 2) penicillin and $\mathrm{TSH}$ on addition to the medium did not change the quantity, and 3) the amount of activity isolated was directly proportional to the number of counts added as glucose. The contaminant was completely removed by acidification with $\mathrm{H}_{2} \mathrm{SO}_{4}$ of the aqueous solution of the glucose-1- $\mathrm{C}^{14}$, treatment with $\mathrm{CO}_{2}$, and deionization by passage through a Duolite-C-3 ion-exchange column in the $\mathrm{H}^{+}$form packed above Duolite- $\mathrm{A}-4$ in the $\mathrm{OH}^{-}$form. Glucose was isolated from the effluent by lyophilization and used in the experiments to be reported. ${ }^{3}$ Glucose6- $\mathrm{C}^{14}$ contained only trace contaminant, but was also purified. In each experiment, control flasks without tissue were incubated and $\mathrm{CO}_{2}$ was collected to assure the absence of $\mathrm{C}^{14} \mathrm{O}_{2}$.

lent per $100 \mathrm{mg}$ of thyroid for nine thyroids). In confirmation of the observations of Freinkel (11), however, only a very small fraction of the reducing substance is glucose as measured with glucose oxidase. Field, Pastan, Herring, and Johnson (4) reported a very low level of glycogen in thyroid glands. Nevertheless, at least $95 \%$ of the $\mathrm{C}^{14}$ found in the ethanol- $\mathrm{KOH}$ precipitate is ascribed to incorporation into glycogen rather than into other substances present in the precipitate. This is done since osazones formed after addition of glucose as carrier to samples of hydrolysates treated with glucose oxidase contained, after recrystallization and washing with water, less than $5 \%$ of the $\mathrm{C}^{14}$ activity in osazones formed from samples not treated with oxidase. These controls were performed with hydrolysates of precipitates obtained from thyroid slices incubated with glucose at 1 and $10 \mathrm{mg}$ per $\mathrm{ml}$ in the presence as well as in the absence of TSH.

2 New England Nuclear Corp., Boșton, Mass.

3 Because of relatively small quantity of glucose oxidized by the thyroid, if contamination is not considered, results may be distorted. The distortion is greater: 1 )
Fructose-1- $\mathrm{C}^{14},-2-\mathrm{C}^{14}$, and $-6-\mathrm{C}^{14}$ were prepared from the corresponding specifically labeled glucoses by the method of Muntz and Carroll (16), except that an intermediate step was introduced in which the fructose was incubated with glucose oxidase in the presence of a small quantity of nonradioactive glucose, the solution was deionized, and the fructose was then isolated by paper chromatographic techniques. This additional procedure was introduced to assure removal of any trace contamination by radioactive glucose.

Glucose-2-C $\mathrm{C}^{14}$ and mannitol-1- $\mathrm{C}^{14}$ were obtained commercially. ${ }^{4}$

The following hormones and other materials were used: a TSH preparation (lot 216-175-5) with an activity of approximately 0.9 U.S.P. U per $\mathrm{mg}^{5}$ and as Thytropar (lots W-5305 and X-5806); ${ }^{6}$ purified TSH preparations assaying at 7.2 (prep. 14-93A) and $30 \mathrm{U}$ per $\mathrm{mg}$ (prep. Fl-51B2); 7 glucagon-free insulin (lot 499667) and glucagon (lot 258-234B-167-1) ; 8 bovine growth hormone (lot P6108), ACTH (lot P67508C), and bovine prolactin, as Panlitar (lot S10209) ; ${ }^{6}$ ovine follicle-stimulating hormone (FSH) (NIH-FSH-S1), and ovine luteinizing hormone (LH) (NIH-LH-S4) ; ${ }^{9}$ L-epinephrine, added as bitartrate; ${ }^{10}$ bovine crystalline plasma albumin (lot W69102) ; ${ }^{6}$ gelatin U.S.P.; ${ }^{11}$ and adenosine $3^{\prime}, 5^{\prime}$-monophosphate, adenosine $3^{\prime}$-monophosphate, and adenosine $5^{\prime}$-monophosphate. ${ }^{12}$

Calculations. Radioactive data are recorded as micrograms of labeled substrate oxidized to $\mathrm{CO}_{2}$ or incorporated into glycogen per $100 \mathrm{mg}$ wet weight of slices per period of incubation. These have been calculated from the radioactivity in the $\mathrm{CO}_{2}$ and glycogen and the specific activity of the labeled substrate in the following manner: (counts per minute in $\mathrm{CO}_{2}$ or glycogen per $100 \mathrm{mg}$ slices)/ (counts per minute per microgram of substrate) $=$ micro-

the larger the concentration of glucose in the medium, since the quantity of contaminant is directly proportional to the $\mathrm{C}^{14}$ in the glucose added, whereas the increase in oxidation is less than proportional, and 2) the shorter the incubation period. Wood and associates (14), in studies of the oxidation of glucose-1- $\mathrm{C}^{14}$ to $\mathrm{CO}_{2}$ by the perfused mammary gland, found it necessary to consider such contamination. Hoskin (15) also noted this contaminant in glucose $\mathrm{C}^{14}$ preparations and indicated that when these preparations are used under certain conditions, corrections must be made.

${ }^{4}$ National Bureau of Standards, Washington, D. C.

5 Provided by Armour Pharmaceutical Co., Chicago, Ill.

${ }^{6}$ Purchased from Armour Pharmaceutical Co., Chicago, III.

${ }^{7}$ Gifts of Dr. Peter Condliffe, National Institutes of Health, Bethesda, Md.

${ }^{8}$ Gifts of Eli Lilly Co., Indianapolis, Ind.

9 Obtained from the Endocrinology Study Section, National Institutes of Health, Washington, D. C.

${ }^{10} \mathrm{~K}$ and $\mathrm{K}$ Laboratories, Inc., Long Island, N. Y. 11 J. T. Baker Chemical Co., Phillipsburg, N. J. 12 Schwarz Laboratories, Inc., Mount Vernon, N. Y. 


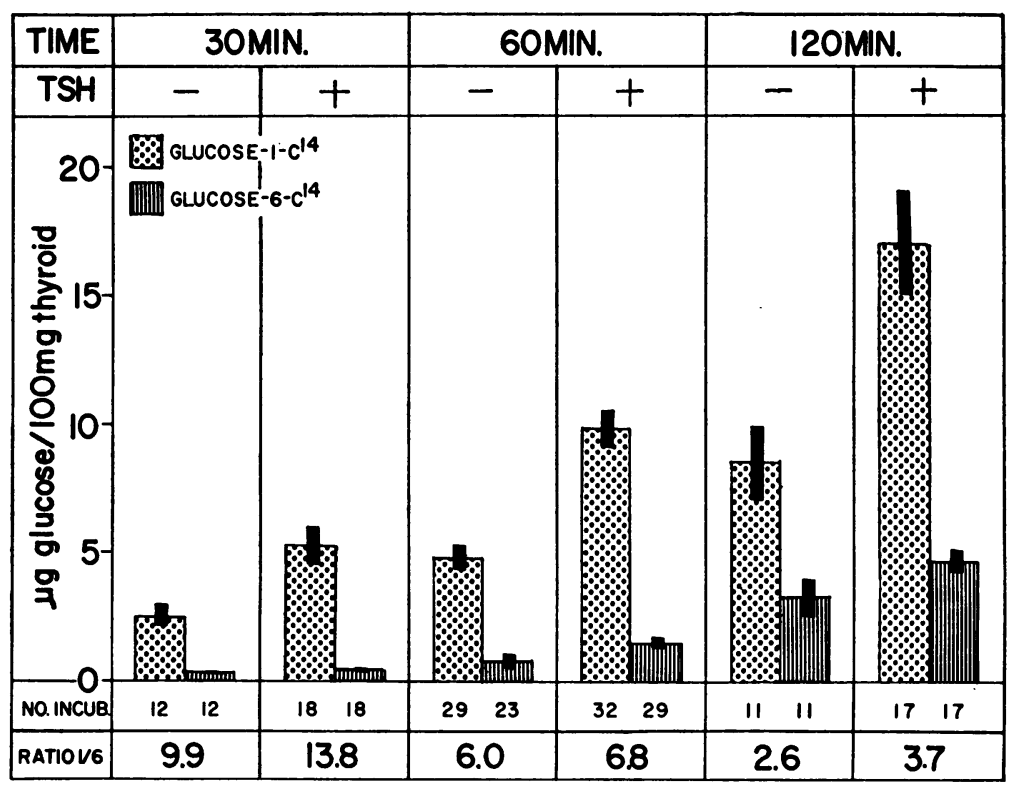

Fig. 1. Oxidation of glucose-1-C ${ }^{14}$ and $-6-C^{14}$ to $\mathrm{C}^{14} \mathrm{O}_{2}$ With time in THE ABSENCE AND PRESENCE OF THYROTROPIC HORMONE (TSH). Glucose concentration was $1 \mathrm{mg}$ per $\mathrm{ml}$ and $\mathrm{TSH}$ concentration, $0.5 \mathrm{U}$ per $\mathrm{ml}$. Each column and associated solid bar represents the mean $\pm \mathrm{SE}$ for the number of incubations recorded below each column. The ratio of the yield of $\mathrm{C}^{14} \mathrm{O}_{2}$ from $\mathrm{C}-1$ and $\mathrm{C}-6$ for each period of time in the absence $(-)$ and presence $(+)$ of $\mathrm{TSH}$ is also presented.

grams of substrate oxidized to $\mathrm{CO}_{2}$ or incorporated into glycogen per $100 \mathrm{mg}$ slices. In each experiment, slices from one thyroid gland were distributed in a number of vessels so that responses to several conditions could be examined. In some experimental designs, insufficient slices from one gland were available to permit examination of all the conditions desired. In this circumstance, an experiment with one gland was performed under some of the conditions, and in a second experiment with another gland, the other conditions were examined. Mean and standard error of the results of the incubations under each condition are recorded. The number of incubations, as recorded in the data to be presented, therefore represents the results obtained on incubating that number of vessels under the specified condition, each vessel containing slices from a different thyroid gland. Where comparisons of responses to the different conditions could be made in the same group of thyroids, standard errors were obtained with the mean square error term of the analysis of variance used to reduce the contribution of animal variation (17).

\section{RESULTS}

Maximal TSH effect and incubation time. Studies were performed at a medium glucose concentration of $1 \mathrm{mg}$ per $\mathrm{ml}$. In the initial experiments, the effect of adding a TSH preparation,
$0.9 \mathrm{U}$ per $\mathrm{mg}$, in a concentration of $0.25,0.5$, and $1.0 \mathrm{U}$ per $\mathrm{ml}$ on the oxidation of glucose-1-C $\mathrm{C}^{\mathbf{1 4}}$ to $\mathrm{CO}_{2}$ during a 1-hour incubation was determined. A maximal response was obtained at 0.5 $\mathrm{U}$ per $\mathrm{ml}$, and this concentration was used in subsequent experiments unless otherwise indicated. In Figure 1 the results on incubation of glucose-1-C $\mathrm{C}^{14}$ and $-6-\mathrm{C}^{14}$ in the absence and presence of TSH, $0.9 \mathrm{U}$ per $\mathrm{mg}$, for periods of 30,60 , and 120 minutes are recorded. TSH increased the oxidation of both $\mathrm{C}-1$ and $\mathrm{C}-6$ to $\mathrm{CO}_{2}$. The ratio of $\mathrm{CO}_{2}$ yield from $\mathrm{C}-1$ compared to C-6 decreased with time. Field and associates $(2,18)$ have made similar observations. During the first 30 minutes, the ratio appeared higher in the presence than in the absence of TSH, but despite the number of observations, this result is not statistically significant $(\mathrm{p}>0.05)$.

Effect of increasing glucose concentration. When the medium glucose concentration was increased to $10 \mathrm{mg}$ per $\mathrm{ml}$ (Figure 2), both the oxidation of $\mathrm{C}-1$ and $\mathrm{C}-6$ of glucose to $\mathrm{CO}_{2}$ was greater than at $1 \mathrm{mg}$ per $\mathrm{ml}$ (see Figure 1), and $\mathrm{TSH}$ increased this oxidation. These increases 
at $10 \mathrm{mg}$ compared to $1 \mathrm{mg}$ per $\mathrm{ml}$ are presumably attributable to a greater availability of glucose intracellularly resulting from the higher concentration of glucose presented to the slice. In an effort to eliminate possible physical effects of the high concentration, for example, osmotic changes, glucose at $1 \mathrm{mg}$ per $\mathrm{ml}$ was incubated in the absence and presence of mannitol at $9 \mathrm{mg}$ per $\mathrm{ml}$. The mannitol was selected as a relatively nonmetabolized sugar, which might reproduce the physical effects of a high concentration of glucose. Only a negligible quantity of $\mathrm{C}^{14} \mathrm{O}_{2}$ was formed on incubation of mannitol-1- $\mathrm{C}^{14}$ with thyroid slices. The presence of mannitol proved without influence on the oxidation of glucose1-C ${ }^{14}$ and $-6-\mathrm{C}^{14}$ to $\mathrm{C}^{14} \mathrm{O}_{2}$ in the absence and presence of TSH.

The C-1 to C- 6 ratios observed at a glucose concentration of $1 \mathrm{mg}$ per $\mathrm{ml}$ in the presence of TSH (Figure 1) are compared with the ratios at a concentration of $10 \mathrm{mg}$ per $\mathrm{ml}$ in the absence of TSH (Figure 2). For the same quantity of C-1 of glucose oxidized, a proportionally greater quantity of C- 6 was oxidized at the higher than the lower concentration. For example, $5.24 \mu \mathrm{g}$ of glucose-1-C $\mathrm{C}^{14}$ and $0.38 \mu \mathrm{g}$ of glucose-6- $\mathrm{C}^{14}$ (ratio
13.8) were oxidized to $\mathrm{CO}_{2}$ at a concentration of glucose of $1 \mathrm{mg}$ per $\mathrm{ml}$ in the presence of TSH after 30 minutes incubation. In contrast, when $5.49 \mu \mathrm{g}$ of glucose-1-C $\mathrm{C}^{\mathbf{1 4}}$ at a concentration of 10 $\mathrm{mg}$ per $\mathrm{ml}$ was oxidized to $\mathrm{CO}_{2}$ in the absence of TSH (60-minute period in Figure 2), $1.43 \mu \mathrm{g}$ of glucose-6-C ${ }^{14}$ (ratio 3.8) was oxidized.

Quantitative estimation of $P C$. The ratio of the yield of $\mathrm{C}-1$ and $\mathrm{C}-6$ to $\mathrm{CO}_{2}$ in the absence of $\mathrm{TSH}$, although much greater than 1, does not quantitate the percentage of glucose metabolized by the $\mathrm{PC}$, and the increase in ratio with $\mathrm{TSH}$ may not reflect a change in this percentage. Katz and Wood (19) have presented a method for quantitating the contribution of the $\mathrm{PC}$ to glucose metabolism. It is based upon the randomization of $\mathrm{C}^{14}$ of labeled glucose during its incorporation into glycogen. Table I records the distribution of $\mathrm{C}^{14}$ in glycogen on incubation of glucose-2- $\mathrm{C}^{14}$ with thyroid slices for 30 and 120 minutes in the absence and presence of TSH. At 30 minutes, the randomization pattern ( $\mathrm{C}-1$ to $\mathrm{C}-2$ ratios) is that to be expected for a $\mathrm{PC}$ contribution of about $3 \%$ in the absence of TSH and $12 \%$ in the presence of TSH. At 120 minutes, the estimations ranged from 3 to $5 \%$, with only a slight

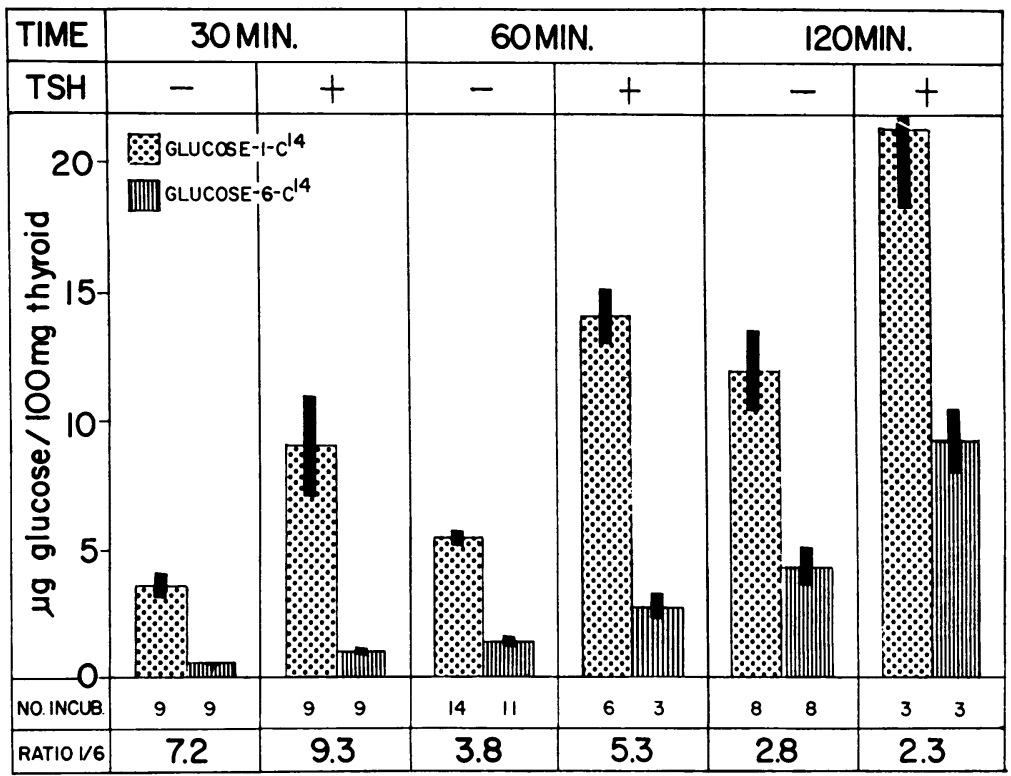

Fig. 2. Oxidation of glucose-1-C $C^{14}$ and $-6-C^{14}$ to $\mathrm{C}^{14} \mathrm{O}_{2}$ with time in THE ABSENCE AND PRESENCE OF THYROTROPIC HORMONE (TSH). Experiments and representation as in Figure 1 except that glucose concentration was $10 \mathrm{mg}$ per $\mathrm{ml}$. 
TABLE I

Percentage of glucose metabolized by the pentose cycle*

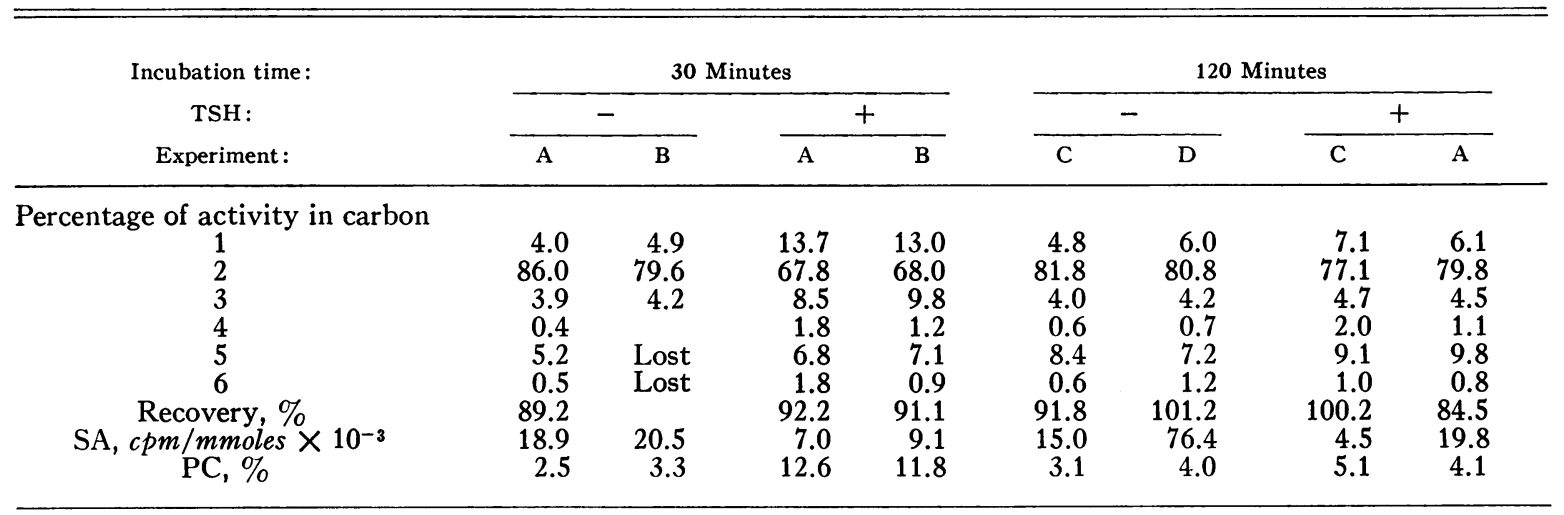

* Glucose-2-C ${ }^{14}, 1 \mathrm{mg}$ per $\mathrm{ml}$, was incubated with thyroid slices, and glycogen was isolated and degraded in four experiments designated A through D. Percentage of distribution of activity in the six carbons of the glucose from glycogen is recorded for incubations at 30 and 120 minutes in the absence $(-)$ and presence $(+)$ of thyrotropic hormone (TSH). The percentage of recovery represents the percentage of activity in the glucose degraded, measured by total combustion, which was recovered as measured by the sum of the activities in the individual carbons. Specific activity of the glucose degraded and percentage of the pentose cycle (PC) estimated from the distribution in C-1 and C-2 (19) for each degradation are also recorded. The percentage of distribution obtained on degradation of the glucose-2-C ${ }^{14}$ employed in the incubations was $0.0,99.1,0.4,0.0,0.4$, and 0.1 for $\mathrm{C}-1$ through $\mathrm{C}-6$, respectively, with a recovery of $91.5 \%$.

trend toward the greater quantity in the presence of TSH.

In these estimations, isotopic equilibration between glucose 6-phosphate and fructose 6-phosphate is assumed. In Table II, data are recorded for experiments performed to test this assumption. In these experiments, glucose and fructose were $a$ ) incubated separately, each labeled with
$\mathrm{C}^{14}$ in the 1- or 6-position and $b$ ) incubated together with only one of the hexoses bearing label. The ratio of yields of $\mathrm{C}^{14}$ in $\mathrm{CO}_{2}$ from $\mathrm{C}-1$ compared to C-6 when fructose was labeled approached, but did not attain, the ratio with labeled glucose whether or not TSH was present. The differences, however, are not statistically significant except when both substrates were to-

TABLE II

Comparison of fructose and glucose oxidation to $\mathrm{CO}_{2}{ }^{*}$

\begin{tabular}{|c|c|c|c|c|c|c|}
\hline \multicolumn{3}{|c|}{ Condition } & \multirow[b]{2}{*}{ Fructose- $\mathrm{C}^{14}$} & \multirow[b]{2}{*}{ Ratio 1:6 } & \multirow[b]{2}{*}{ Glucose-C14 } & \multirow[b]{2}{*}{ Ratio 1:6 } \\
\hline TSH & $\begin{array}{l}\text { Unlabeled } \\
\text { hexose }\end{array}$ & $\underset{\text { carbon }}{\mathrm{Cl}^{14}}$ & & & & \\
\hline & & & $\begin{array}{c}\mu g s \text { to } \mathrm{C}^{14} \mathrm{O}_{2} / 100 \\
\text { mg thyroid }\end{array}$ & & $\begin{array}{c}\mu g s \text { to } \mathrm{C}^{14} \mathrm{O}_{2} / 100 \\
\text { mg thyroid }\end{array}$ & \\
\hline- & - & $\begin{array}{l}1 \\
6\end{array}$ & $\begin{array}{l}1.65 \pm 0.13 \\
0.71 \pm 0.13\end{array}$ & $2.42 \pm 0.23$ & $\begin{array}{l}8.88 \pm 1.2 \\
3.22 \pm 0.26\end{array}$ & $\begin{array}{l}3.03 \pm 0.56 \\
\mathrm{p}>0.3\end{array}$ \\
\hline+ & - & $\begin{array}{l}1 \\
6\end{array}$ & $\begin{array}{l}2.37 \pm 0.13 \\
0.78 \pm 0.19\end{array}$ & $3.22 \pm 0.28$ & $\begin{array}{c}13.3 \pm 0.97 \\
4.34 \pm 0.81\end{array}$ & $\begin{array}{l}3.50 \pm 0.39 \\
\mathrm{p}>0.7\end{array}$ \\
\hline- & + & $\begin{array}{l}1 \\
6\end{array}$ & $\begin{array}{l}0.54 \pm 0.09 \\
0.24 \pm 0.03\end{array}$ & $2.29 \pm 0.17$ & $\begin{array}{l}4.26 \pm 0.41 \\
1.69 \pm 0.20\end{array}$ & $\begin{array}{l}2.74 \pm 0.55 \\
\mathrm{p}>0.4\end{array}$ \\
\hline+ & + & $\begin{array}{l}1 \\
6\end{array}$ & $\begin{array}{l}1.08 \pm 0.23 \\
0.47 \pm 0.11\end{array}$ & $2.30 \pm 0.11$ & $\begin{array}{c}12.5 \pm 1.7 \\
3.38 \pm 0.64\end{array}$ & $\begin{array}{l}3.91 \pm 0.33 \\
p<0.01\end{array}$ \\
\hline
\end{tabular}

* Fructose-1-C $\mathrm{C}^{14}$ and $-6-\mathrm{C}^{14}$ were incubated for 2 hours in the absence $(-)$ and presence $(+)$ of thyrotropic hormone (TSH), $0.5 \mathrm{U}$ per $\mathrm{ml}$. Glucose-1-C ${ }^{14}$ and $-6-\mathrm{C}^{14}$ were incubated in parallel flasks. Yields of $\mathrm{C}^{14} \mathrm{O}_{2}$ from $\mathrm{C}-1$ and $\mathrm{C}-6$ of fructose and glucose and the ratios of the yields are recorded. Results when unlabeled hexose was absent $(-)$ are the means and SE of 10 incubations in which the flasks contained either labeled fructose or glucose at a concentration of $1 \mathrm{mg}$ per $\mathrm{ml}$. Results when unlabeled hexose was present $(+)$ are the means $\pm \mathrm{SE}$ of five incubations in which flasks contained both fructose and glucose, each at a concentration of $1 \mathrm{mg}$ per $\mathrm{ml}$, but with only one of the hexoses labeled as indicated. The p value is obtained by $t$ comparison for paired observations of the ratios obtained with glucose compared to the ratios obtained with fructose. 


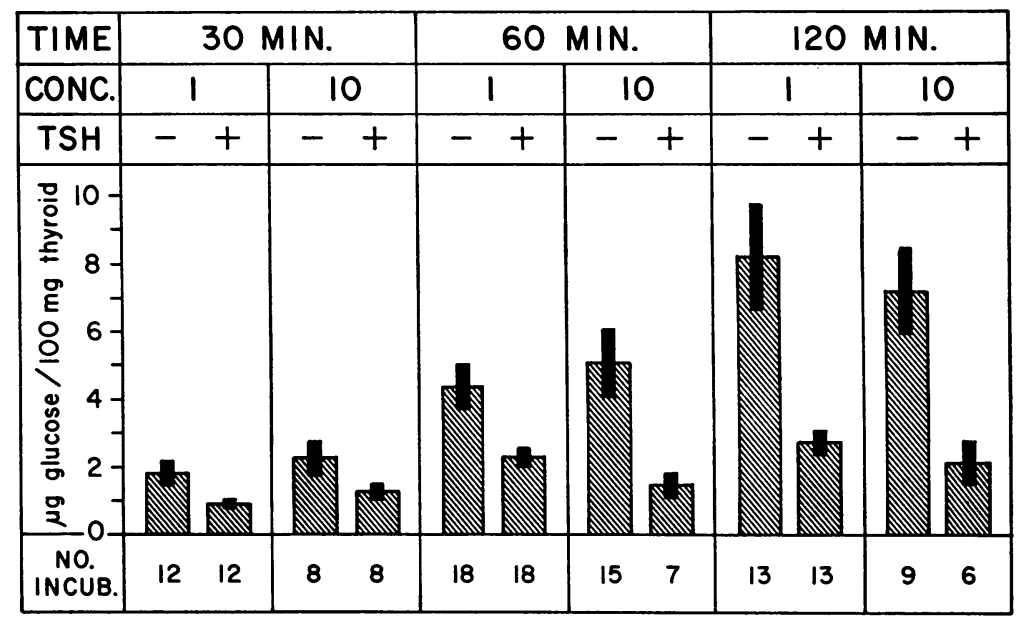

Fig. 3. EFFeCt OF THYROTROPIC HORMONE (TSH) ON THE INCORPORATION of GLucose-C ${ }^{14}$ into glycogen. Glucose- $\mathrm{C}^{14}$, either C-1 or C-6 labeled, was present at a concentration of 1 or $10 \mathrm{mg}$ per $\mathrm{ml}$ as indicated. Column and bar representations are as in Figure 1.

gether in the presence of TSH. Between one-fifth and one-twelfth as much fructose as glucose was oxidized to $\mathrm{CO}_{2}$. These results are for incubations lasting 2 hours. Fructose-2- $\mathrm{C}^{14}$ was also incubated with thyroid slices in the absence of $\mathrm{TSH}$, and the glucose from glycogen degraded. Randomization (Table III) was similar, though suggestively less than when glucose-2-C $\mathrm{C}^{14}$ was substrate.

TSH effect on glycogen. The quantity of glucose incorporated into glycogen at glucose concentrations of 1 and $10 \mathrm{mg}$ per $\mathrm{ml}$ in the absence and presence of TSH is illustrated in Figure 3. Incorporation consistently was less in the presence than in the absence of TSH.

Effects of other hormones. Insulin, $0.5 \mathrm{U}$ per $\mathrm{ml}$, in contrast to TSH, did not influence the oxidation of glucose-1-C $\mathrm{C}^{14}$ and fructose-1-C $\mathrm{C}^{14}$ to $\mathrm{C}^{14} \mathrm{O}_{2}$ and their incorporation into glycogen. Epinephrine at a concentration of $10^{-4} \mathrm{M}$ in-

TABLE III

Distribution in glycogen on incubation with fructose-2-C 14* $^{14}$

\begin{tabular}{|c|c|c|c|c|c|c|c|c|}
\hline \multirow{2}{*}{$\begin{array}{c}\text { Experi- } \\
\text { ment }\end{array}$} & \multicolumn{6}{|c|}{ Percentage of activity in carbon } & \multirow{2}{*}{$\begin{array}{c}\mathrm{Re}- \\
\text { covery }\end{array}$} & \multirow{2}{*}{$\begin{array}{l}\text { Pen- } \\
\text { tose } \\
\text { cycle }\end{array}$} \\
\hline & 1 & 2 & 3 & 4 & 5 & 6 & & \\
\hline & & & & & & & $\%$ & $\%$ \\
\hline$\underset{F}{E}$ & $\begin{array}{l}3.0 \\
4.1\end{array}$ & $\begin{array}{l}83.9 \\
81.0\end{array}$ & $\begin{array}{l}2.8 \\
4.3\end{array}$ & $\begin{array}{l}0.9 \\
1.7\end{array}$ & $\begin{array}{l}8.5 \\
7.1\end{array}$ & $\begin{array}{l}0.9 \\
1.8\end{array}$ & $\begin{array}{l}90.4 \\
90.8\end{array}$ & $\begin{array}{l}1.9 \\
2.7\end{array}$ \\
\hline
\end{tabular}

* Fructose-2-C14, $1 \mathrm{mg}$ per $\mathrm{ml}$, was incubated for 2 hours in the absence of thyrotropic hormone (TSH). Glucose from glycogen was
solated and degraded. Presentation is as in Table I. creased the oxidation of glucose-1-C $\mathrm{C}^{14}$ to $\mathrm{C}^{14} \mathrm{O}_{2}$, although not to so great an extent as $\mathrm{TSH}$ at a concentration of $0.5 \mathrm{U}$ per ml. Glucagon, $10 \mu \mathrm{g}$ per $\mathrm{ml}$, was without effect. Epinephrine, however, in contrast to TSH, did not decrease the incorporation of glucose into glycogen. No effect was noted when thyroid slices were incubated with adenosine $3^{\prime}, 5^{\prime}$-monophosphate (cyclic $3^{\prime}, 5^{\prime}$ AMP) at $10^{-5}$ to $10^{-2} \mathrm{M}$. Adenosine $3^{\prime}$-monophosphate and adenosine $5^{\prime}$-monophosphate were also without effect.

Comparison of TSH preparations. The Armour TSH preparation, $0.9 \mathrm{U}$ per $\mathrm{mg}$, and a more extensively purified preparation, $30 \mathrm{U}$ per mg, were compared by incubating slices in their absence and presence, both at a concentration of $0.5 \mathrm{U}$ per $\mathrm{ml}$. The increase observed in the oxidation of glucose-1- $\mathrm{C}^{14}$ to $\mathrm{C}^{14} \mathrm{O}_{2}$ and the decrease in $\mathrm{C}^{14}$ incorporation into glycogen was the same for both preparations.

Effect of concentration of TSH. In the experiments described thus far, the TSH concentration was $0.5 \mathrm{U}$ per $\mathrm{ml}$. After observing the effects of $\mathrm{TSH}$ at this concentration on the oxidation of glucose to $\mathrm{CO}_{2}$ and its incorporation into glycogen, a series of experiments was performed to determine at what concentration the effects disappeared. To avoid the adsorption on glassware of $\mathrm{TSH}$, when present at low concentration, albumin, $1 \mathrm{mg}$ per $\mathrm{ml}$, was added to the medium (20). In 
preliminary experiments, gelatin, $1 \mathrm{mg}$ per $\mathrm{ml}$, was also used (21). Field and associates (2) have previously presented data suggesting that albumin decreases glucose oxidation. Neither albumin nor gelatin appeared to change the quantity of glucose-1-C ${ }^{14}$ oxidized to $\mathrm{CO}_{2}$ or incorporated into glycogen when compared with a medium without these additions. The response to TSH with decreasing concentrations appeared the same whether Thytropar or a TSH preparation, 7.2 U per $\mathrm{mg}$, was used. In almost all of the incubations, the results of which are now to be presented, the latter preparation was employed. The results for the different TSH concentrations are reported as a percentage of the buffer value, the response when no TSH was present.

Slices from 15 thyroids were incubated with $\mathrm{TSH}$ for 1 hour at five concentrations ranging from 0.5 to $0.0008 \mathrm{U}(0.8 \mathrm{mU})$ per $\mathrm{ml}$. The incorporation of glucose-1- $\mathrm{C}^{14}$ into glycogen was decreased to about $50 \%$ of the buffer value at all the concentrations tested. At $0.5 \mathrm{U}$ per $\mathrm{ml}$, oxidation to $\mathrm{C}^{14} \mathrm{O}_{2}$ was increased to $391 \%$ of the buffer value, but this response was less with de-

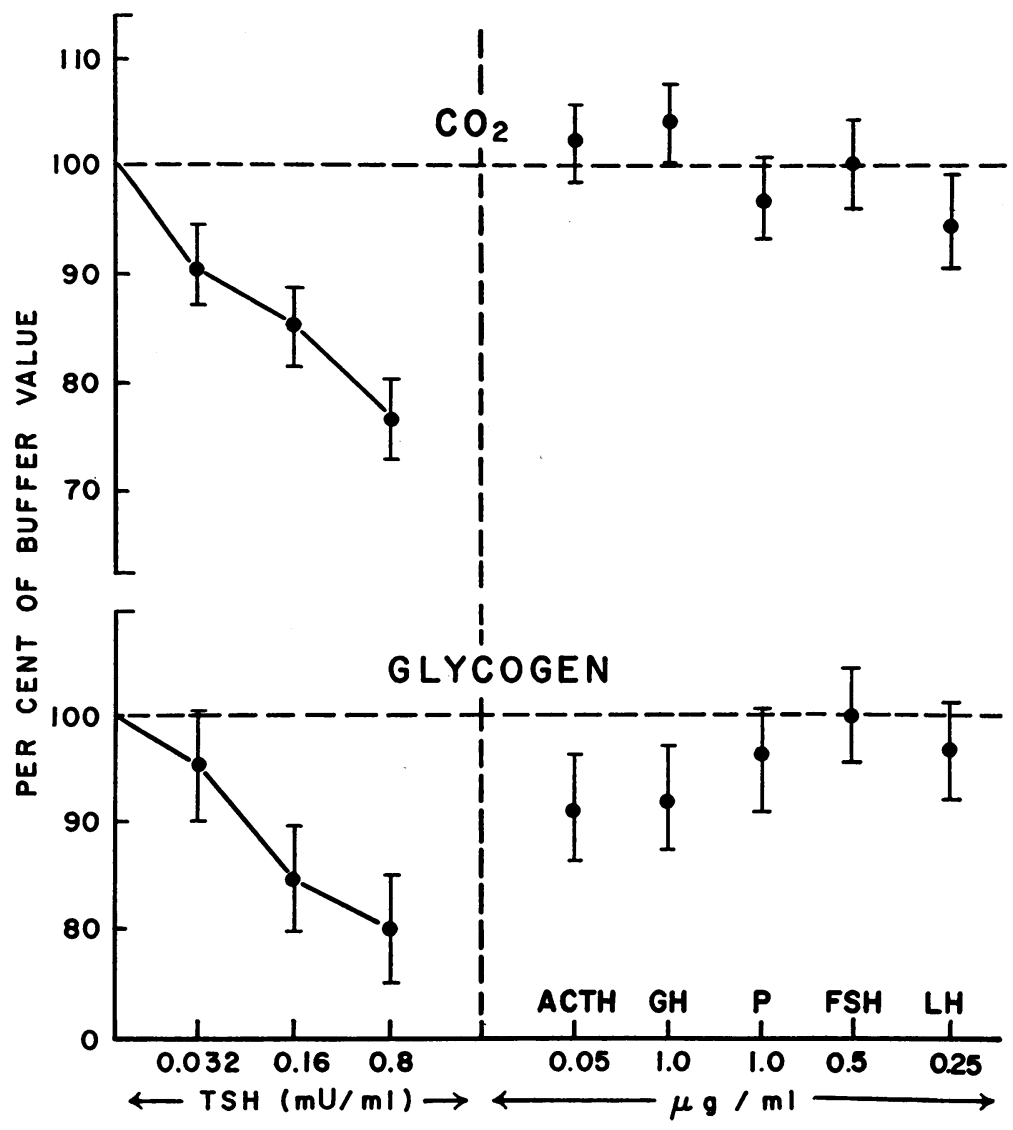

Fig. 4. Oxidation of glucose-1- $\mathrm{C}^{14}$ to $\mathrm{C}^{14} \mathrm{O}_{2}$ and its incorporation INTO GLYCOGEN. Incubations were for 60 minutes with slices from 10 thyroids, and TSH concentrations ranged from $0.032 \mathrm{mU}$ to $0.8 \mathrm{mU}$ per ml. Mean responses are represented as the percentage of the value observed in the absence of TSH. SE have been calculated by the analysis of variance. The decreases below base line in the oxidation to $\mathrm{CO}_{2}$ and incorporation into glycogen at TSH concentrations of $0.8 \mathrm{mU}$ per $\mathrm{ml}$ and $0.16 \mathrm{mU}$ per $\mathrm{ml}$ are significant at $\mathrm{p}<0.01$. Results of parallel incubations with $\mathrm{ACTH}$, growth hormone $(\mathrm{GH})$, prolactin $(\mathrm{P})$, follicle-stimulating hormone $(\mathrm{FSH})$, and luteinizing hormone $(\mathrm{LH})$ are also presented. Glucose and albumin were each at a concentration of $1 \mathrm{mg}$ per $\mathrm{ml}$. 
creasing concentrations, so that a depression of oxidation below base line was suggested at a concentration of $0.0008 \mathrm{U}$ per $\mathrm{ml}$. Incubations of slices from an additional 11 thyroids in the absence of TSH and in its presence at $0.8 \mathrm{mU}$ per $\mathrm{ml}$ and $0.1 \mathrm{U}$ per $\mathrm{ml}$ yielded similar results. In the presence of $0.8 \mathrm{mU}$ per $\mathrm{ml}$ of $\mathrm{TSH}$, incorporation of glucose-1- $\mathrm{C}^{14}$ into glycogen was $79 \pm 4 \%$ and oxidation to $\mathrm{C}^{14} \mathrm{O}_{2}, 80 \pm 4 \%$ of base-line values. At a concentration of $0.1 \mathrm{U}$ per $\mathrm{ml}$, TSH depressed incorporation to $50 \%$ and increased oxidation to $266 \%$ of base line. In another series of experiments, where lower concentrations were tested (Figure 4), the effect of TSH on incorporation into glycogen was observed to a concentration of $0.16 \mathrm{mU}$ per $\mathrm{ml}$. At this concentration, the quantity of $\mathrm{C}^{14} \mathrm{O}_{2}$ formed from glucose-1-C $\mathrm{C}^{14}$ was less than that in the absence of TSH. Parallel incubations were performed (Figure 4) with preparations of ACTH, $0.05 \mu \mathrm{g}$ per $\mathrm{ml}$; growth hormone, $1 \mu \mathrm{g}$ per $\mathrm{ml}$; prolactin, $1 \mu \mathrm{g}$ per $\mathrm{ml}$; FSH, $0.5 \mu \mathrm{g}$ per $\mathrm{ml}$; and LH, $0.25 \mu \mathrm{g}$ per $\mathrm{ml}$. These did not significantly affect the oxidation of glucose-1- $\mathrm{C}^{14}$ to $\mathrm{C}^{14} \mathrm{O}_{2}$ or the incorporation of $\mathrm{C}^{14}$ into glycogen. Incubations of slices from nine thyroids were also performed with $\mathrm{LH}, \mathrm{FSH}$, growth hormone, and $\mathrm{ACTH}$, each at a concentration of $2.5 \mu \mathrm{g}$ per ml. Incorporation into glycogen of glucose-1-C ${ }^{14}$ was $78 \%$ for $\mathrm{LH}, 94 \%$ for FSH, $85 \%$ for growth hormone, and $89 \%$ for ACTH of the base-line buffer value, whereas $\mathrm{TSH}, 0.1 \mathrm{U}$ per $\mathrm{ml}$, decreased the incorporation to $48 \%$. The standard error of the series was $\pm 7 \%$. The effect of the $\mathrm{LH}$ preparation is in accord with its content of TSH $0.06 \mathrm{mU}$ per $\mu \mathrm{g}$, as reported by the Endocrinology Study Section. ${ }^{13}$

Incubations of 30 minutes duration were also performed (Figure 5). TSH significantly decreased incorporation of glucose into glycogen at a concentration of $0.032(\mathrm{p}<0.05)$, but not $0.0064 \mathrm{mU}$ per ml. Again the oxidation of glucose-1- $\mathrm{C}^{14}$ to $\mathrm{C}^{14} \mathrm{O}_{2}$ was depressed below the control value at these low TSH concentrations.

\section{DISCUSSION}

The thyroid-slice system employed in these studies is parallel in response to that described by Field and associates (2) and Schussler and Ingbar

${ }^{13}$ National Institutes of Health, Washington, D. C.
(22) in that: 1) TSH increased the oxidation of $\mathrm{C}-1$ and $\mathrm{C}-6$ of glucose to $\left.\mathrm{CO}_{2} ; 2\right)$ the C-1 : C-6 ratio of $\mathrm{C}^{14} \mathrm{O}_{2}$ yields appeared greater in the presence than the absence of TSH, at least during the initial period of incubation; and 3) the quantity of TSH producing these effects was large when compared to probable physiological concentrations. Dumont (20) noted an increase in glucose oxidation to $\mathrm{CO}_{2}$ at a TSH concentration of $1 \mathrm{mU}$ per $\mathrm{ml}$, under conditions in which albumin was added to the incubation medium, and Field and co-workers (4) observed effects at $0.05 \mathrm{mU}$ per $\mathrm{ml}$ in canine thyroid glands.

$\mathrm{C}^{14} \mathrm{O}_{2}$ production from glucose- $1-\mathrm{C}^{14}$ and $-6-\mathrm{C}^{14}$ does not of itself reflect the contribution of the PC to the metabolism of glucose, but estimations based upon the randomization of glucose-2- $\mathrm{C}^{14}$ do (19). Results obtained by this method indicate that only a small percentage of the total quantity of glucose utilized by the thyroid is metabolized via the PC. At least during the early period of TSH incubation, however, a manifold increase in PC contribution appears to occur. The accompanying increase in TPNH could have profound effects upon metabolism. Dumont (23) has reported changes in $\mathrm{C}-1$ to $\mathrm{C}-6$ ratios of $\mathrm{C}^{14} \mathrm{O}_{2}$ yields from glucose- $\mathrm{C}^{14}$ with time on incubation of thyroid slices in the absence of TSH and has estimated from these yields that $75 \%$ of the $\mathrm{CO}_{2}$ produced from glucose was via the PC.

The estimation of $\mathrm{PC}$ contribution from the randomization of $\mathrm{C}-2$ of glucose during its incorporation into glycogen assumes a system where there is "complete recycling," i.e., isotopic equilibration between glucose 6-phosphate and fructose 6-phosphate. ${ }^{14}$ In this circumstance, a single pool of hexose 6-phosphate may be considered to exist, such that the treatment of the label within the pool is independent of whether the label was originally in glucose or fructose. Thus, the ratio of $\mathrm{C}-1: \mathrm{C}-6$ yields of $\mathrm{C}^{14} \mathrm{O}_{2}$ from glucose- and fructose-1- $\mathrm{C}^{14}$ and $-6-C^{14}$ should be the same. Failure of equilibration would result in a lower ratio for fructose than glucose, since the carbons of fructose 6-phosphate, when compared to the carbons of glucose 6-phosphate, would be preferentially presented to

14 A complete discussion of PC estimations in the presence of incomplete isotopic equilibration is in preparation by B. R. Landau, J. Katz, G. E. Bartsch, and H. G. Wood. 


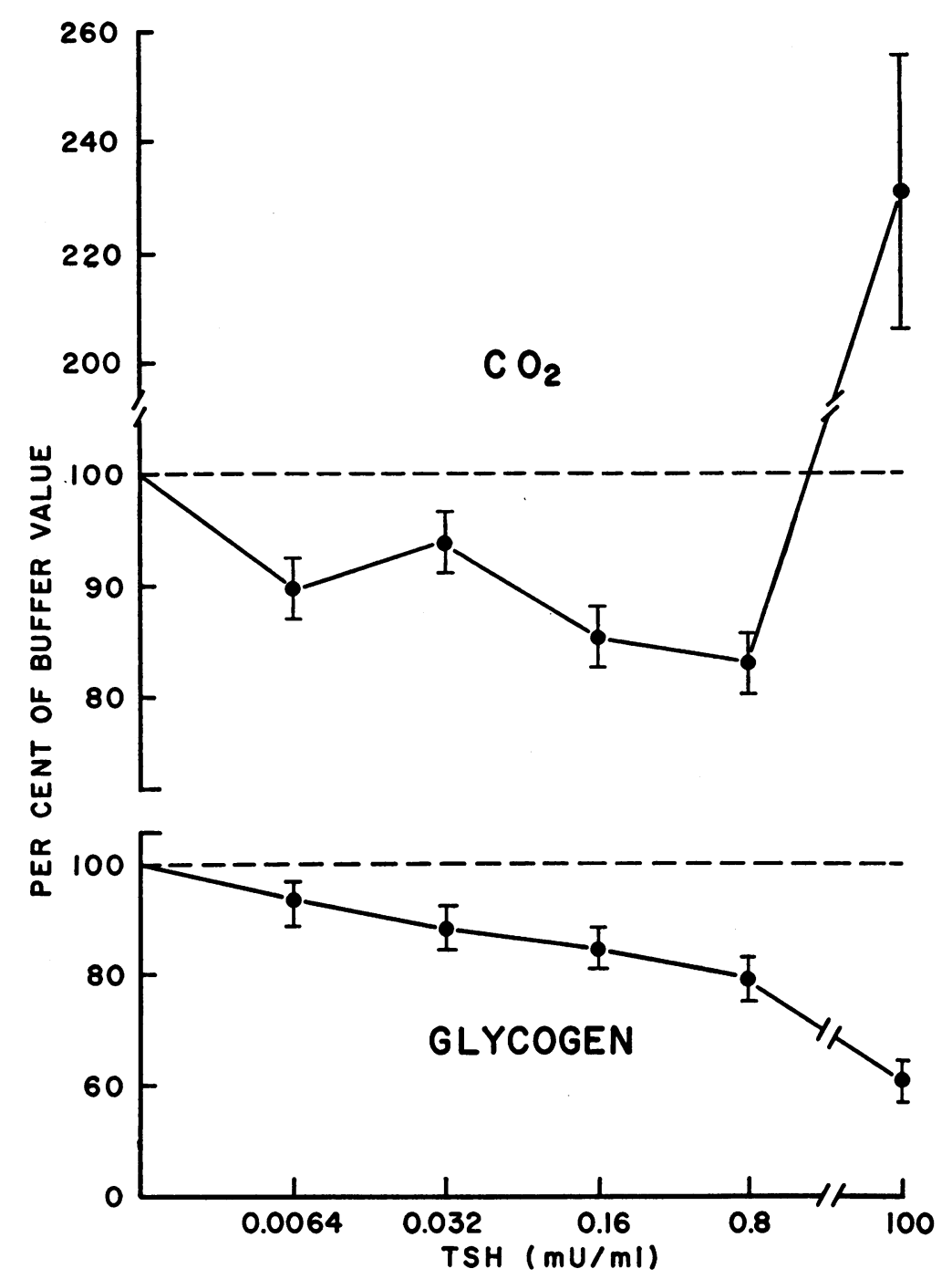

Fig. 5. Oxidation of glucose-1-C ${ }^{14}$ to $\mathrm{C}^{14} \mathrm{O}_{\text {: }}$ and its incorporation INTO GLycogen. Experiments are as in Figure 4 except that incubation was for 30 minutes, and the results are for incubations of slices from 16 thyroids with $\mathrm{TSH}$ concentration ranged from $0.1 \mathrm{U}$ to $0.0064 \mathrm{mU}$ per $\mathrm{ml}$. $\mathrm{SE}$ for concentrations from 0.0064 to $0.8 \mathrm{mU}$ per $\mathrm{ml}$ have been calculated from the analysis of variance. $\mathrm{CO}_{2}$ response at $0.032 \mathrm{mU}$ per $\mathrm{ml}$ is significantly below base line at $\mathrm{p}<0.05$. The average of the four concentrations is significantly below base line with $p<0.001$. The increase in oxidation above base line at $0.1 \mathrm{U}$ per $\mathrm{ml}$ is also highly significant. All glycogen responses are significantly below base line except at a TSH concentration of $0.0064 \mathrm{mU}$ per $\mathrm{ml}$.

the Krebs cycle rather than the PC. That the $\mathrm{CO}_{2}$ ratios for fructose-1-C $\mathrm{C}^{14}$ and $-6-\mathrm{C}^{14}$ approached those for glucose-1- $\mathrm{C}^{14}$ and $-6-\mathrm{C}^{14}$ at a 2-hour incubation (Table II) indicates recycling was extensive, though probably not complete. The comparison between fructose and glucose when incubated separately necessitates the as- sumption that the pathway contributions to $\mathrm{CO}_{2}$ production do not change simply as a consequence of the change in substrate from glucose to fructose. With both substrates together in the incubation medium, this assumption is unnecessary, since substrate conditions, whether the fructose or glucose bears the label, barring isotope effects, 
are identical. Of the four conditions examined (Table II), when TSH and both substrates were present, the greatest quantity of hexose might be expected to be subject to the rate of isomerization of fructose 6-phosphate to glucose 6-phosphate. In accord with this, only in the presence of both substrates and TSH was there a significant difference in the ratio of $\mathrm{CO}_{2}$ yields from fructose and glucose (Table II). Other evidence of extensive recycling is obtained from the similar distribution of $\mathrm{C}^{14}$ in glycogen, whether fructose$2-\mathrm{C}^{14}$ or glucose-2-C $\mathrm{C}^{14}$ was substrate. Again, changes in pathway contributions associated with changes in substrate must be assumed negligible. At less than complete recycling, an estimation with glucose-2-C ${ }^{14}$ randomization is lower than the actual value. Therefore, the PC estimations represent minimal values, but probably close approximations.

A steady-state condition must also be assumed to exist for making these estimations. The longer the period of incubation, the more likely it is to have been attained. Although ratios of $\mathrm{C}^{14} \mathrm{O}_{2}$ yields from glucose-1-C ${ }^{14}$ and $-6-C^{14}$ (Figure 1) had not become constant, at least at 30 minutes, steady state for hexose 6-phosphates may well have been established by this time. This is so, since the achieving of isotopic steady state in a pool will be faster, the smaller the pool and the shorter its distance from the substrate. The similar distributions in glycogen with glucose-2-C $\mathrm{C}^{14}$ as substrate, at 30 and 120 minutes in the absence of $\mathrm{TSH}$, supports the assumption that steady state for the hexose 6-phosphate was achieved within 30 minutes. It is further assumed that fructose is metabolized in thyroid via fructose 6-phosphate and not fructose 1-phosphate. The similar distribution in glycogen whether glucose-2- $\mathrm{C}^{14}$ or fructose-2- $\mathrm{C}^{14}$ was substrate is in accord with this assumption. If metabolism was via fructose 1-phosphate, as in the liver, in comparison to the pattern with glucose-2-C $\mathrm{C}^{14}$, with fructose-2-C ${ }^{14}$, more activity would have been expected in $\mathrm{C}-5$ relative to $\mathrm{C}-2$.

The increase in percentage of $\mathrm{PC}$ with $\mathrm{TSH}$ addition need not be consequent to a direct action of TSH on this pathway. For example, the proportion of glucose that traverses this pathway compared to other pathways could depend upon the concentration of glucose 6-phosphate present and the relative affinities of the pathways for this substrate. Thus, at high glucose 6-phosphate concentrations, other pathways may be saturated so that a greater proportion of glucose will traverse the PC. Field and co-workers (2) did consider the possibility that TSH acted by increasing the intracellular entrance of glucose (and thus the quantity of glucose 6-phosphate). They disposed of this mechanism with the observation that insulin increased glucose uptake by the thyroid slice, but not its oxidation to $\mathrm{CO}_{2}$. This assumes that the greater disappearance of glucose from the medium was the result of an action of insulin on the transport of glucose into the cell. We have been unable to demonstrate either a stimulation of glucose oxidation or glucose incorporation into glycogen on insulin addition. Increasing medium glucose concentration is generally considered another method for studying the effects of increasing the quantity of glucose entering into cells in vitro (24). With increase in glucose concentration, the oxidation of glucose-1-C $\mathrm{C}^{14}$ and $-6-\mathrm{C}^{14}$ to $\mathrm{C}^{14} \mathrm{O}_{2}$ was increased. The $\mathrm{C}-1$ : $\mathrm{C}-6$ ratios were not as large as those noted in the presence of $\mathrm{TSH}$, but this does not negate the possibility that part of the response to TSH addition results from an increase in glucose availability to the cell. Comparisons of $\mathrm{CO}_{2}$ yields at these different glucose concentrations, in the absence and presence of $\mathrm{TSH}$, have been made at specific times during the course of incubations. The comparisons at different time periods are made with reservation, since responses were not linear with time and other relationships may hold at intervals of time not examined.

The increase in the oxidation of glucose and the decrease in its incorporation into glycogen is relatively specific for TSH. Similar effects have been observed with TSH preparations of different purity, so that contamination of the TSH with another material responsible for the effects seems unlikely. Field and co-workers $(2,18)$ observed, as was confirmed in these experiments, no increase in oxidation on addition of ACTH, insulin, FSH, prolactin, and growth hormone, and in addition, we have not with $\mathrm{LH}$ and glucagon. Epinephrine, however, does increase the oxidation of $\mathrm{C}-1$ of glucose to $\mathrm{CO}_{2}$, a result in agreement with the report of Pastan, Herring, Johnson, and Field (25). Neither ACTH, epinephrine, growth hormone, glucagon, $\mathrm{FSH}$, insulin, $\mathrm{LH}$, nor prolactin in the concentrations studied appears to af- 
fect the incorporation of $\mathrm{C}^{14}$ of glucose-1- $\mathrm{C}^{14}$ into glycogen.

Dumont (20) and Pastan and associates (25) have concluded that an increase in oxidation of glucose occurs on addition of TSH at concentrations in the physiological range. Dumont refers to a TSH concentration of $0.5 \mathrm{mU}$ per $\mathrm{ml}$ in human plasma (26). The concentration normally present in blood remains in doubt (27). Thus, for example, the estimate of Bates and Condliffe has recently been revised downward to $0.01 \mathrm{mU}$ per $\mathrm{ml}$ (28). The effect of TSH on the incorporation of glucose into glycogen occurred at concentrations where increases in glucose oxidation were not observed and where yields of $\mathrm{C}^{14} \mathrm{O}_{2}$ were significantly below base line. A decrease in incorporation was detectable at a concentration of $0.032 \mathrm{mU}$ per $\mathrm{ml}(0.005 \mu \mathrm{g}$ per $\mathrm{ml}$ of the TSH preparation employed), whereas an increase in $\mathrm{C}^{14} \mathrm{O}_{2}$ production from glucose-1- $\mathrm{C}^{14}$ was observed only at a much higher concentration. The decrease in the quantity of $\mathrm{C}^{14} \mathrm{O}_{2}$ formed at the low TSH concentrations could be in accord with a dilution of the glucose- $\mathrm{C}^{14}$ entering the thyroid cells by nonlabeled glucose 6-phosphate formed from glycogen breakdown. The significance of the decrease in incorporation of glucose into glycogen, however, remains uncertain, especially with the low concentration of glycogen in the thyroid. Freinkel previously suggested (29) that the primary site of TSH action might be at the preformed intracellular stores of substrates, as glycogen, and noted that the stimulation of thyroid oxygen consumption by TSH in vitro does not require the presence of any organic substrate in the medium.

It was considered possible that a site of action of TSH might be at the level of glycogen breakdown. Such a mechanism would parallel that proposed for ACTH on the phosphorylase system in the adrenal (5) and for chorionic gonadotropin in the corpus luteum (30). In agreement with the observation of Field and co-workers (4), however, cyclic $3^{\prime}, 5^{\prime}$-AMP did not simulate TSH action on thyroid slices. This negative result may be a consequence of the failure of the nucleotide to enter readily into cells. Field and associates (4) reported a very low level of phosphorylase in thyroid. Klainer and co-workers (31) recently reported an apparent increase in the formation of cyclic $3^{\prime}, 5^{\prime}$-AMP on addition of TSH prepara- tions to particulate preparations from sheep thyroid.

\section{SUM MARY}

Beef-thyroid slices have been incubated with specifically labeled glucose under conditions designed to investigate the biochemical effects of thyrotropic hormone (TSH) action on carbohydrate metabolism. The oxidation to $\mathrm{CO}_{2}$ of carbon 1 and carbon 6 of glucose was increased by the addition of a TSH preparation, and the incorporation of the carbons into glycogen decreased. Increasing the concentration of glucose in the incubation medium also increased oxidation, but the C-1 to C- 6 ratio of $\mathrm{C}^{14} \mathrm{O}_{2}$ yields was less than with TSH. From the extent of the randomization of $\mathrm{C}-2$ of glucose and fructose during their incorporation into glycogen and the relative yields of $\mathrm{C}^{14} \mathrm{O}_{2}$ from glucose- and fructose-1- $\mathrm{C}^{14}$ and $-6-\mathrm{C}^{14}$, it is estimated that only a small fraction of the glucose utilized by the thyroid is metabolized via the pentose cycle. This fraction, however, is larger in the presence than absence of TSH. Epinephrine, but neither ACTH, follicle-stimulating hormone $(\mathrm{FSH})$, glucagon, growth hormone, insulin, luteinizing hormone $(\mathrm{LH})$, nor prolactin increased the oxidation of glucose, and none of these decreased the incorporation of glucose carbon into glycogen. The metabolic changes observed on TSH addition do not appear to be ascribable solely to the greater intracellular availability of glucose, and the physiological relevance of the observation of increased oxidation of glucose- $\mathrm{C}^{14}$ to $\mathrm{C}^{14} \mathrm{O}_{2}$ remains uncertain. $A$ decrease in the oxidation of glucose-1-C $\mathrm{C}^{14}$ to $\mathrm{C}^{14} \mathrm{O}_{2}$ and in its incorporation into glycogen occurs at relatively low TSH concentrations.

\section{ACKNOWLEDGMENTS}

The authors were fortunate to have the expert technical assistance of Mr. Hollis R. Williams. We are indebted to Dr. Glenn E. Bartsch for statistical advice and to Drs. Richard P. Levy and Lawrence M. Heideman, Jr., for several helpful suggestions. We appreciate the cooperation of the staff of the Earl C. Gibbs Meat Packing Company.

\section{REFERENCES}

1. Landau, B. R., W. Merlevede, and G. Weaver. Thyrotropic hormone action on carbohydrate metabolism in thyroid slices (abstract). J. clin. Invest. 1962, 41, 1375. 
2. Field, J. B., I. Pastan, P. Johnson, and B. Herring. Stimulation in vitro of pathways of glucose oxidation in thyroid by thyroid-stimulating hormone. J. biol. Chem. 1960, 235, 1863.

3. Pastan, I., B. Herring, and J. B. Field. Changes in diphosphopyridine nucleotide and triphosphopyridine nucleotide levels produced by thyroid-stimulating hormone in thyroid slices in vitro. J. biol. Chem. 1961, 236, PC25.

4. Field, J. B., I. Pastan, B. Herring, and P. Johnson. Studies on the mechanism of action of thyroid stimulating hormone on glucose oxidation. Biochim. biophys. Acta (Amst.) 1961, 50, 513.

5. Haynes, R. C., Jr., E. W. Sutherland, and T. W. Rall. The role of cyclic adenylic acid in hormone action in Recent Progress in Hormone Research, G. Pincus, Ed. New York, Academic Press, 1960, vol. 16, p. 121.

6. Cohen, P. P. Suspending media for animal tissues in Manometric Techniques, 3rd ed., W. W. Umbreit, R. H. Burris, and J. F. Stauffer, Eds. Minneapolis, Burgess, 1957, p. 149.

7. Good, C. A., H. Kramer, and M. Somogyi. The determination of glycogen. J. biol. Chem. 1933, 100, 485 .

8. Landau, B. R. Gluconeogenesis and pyruvate metabolism in rat kidney, in vitro. Endocrinology 1960, 67, 744.

9. Werbin, H., I. L. Chaikoff, and M. R. Imada. Rapid sensitive method for determining $\mathrm{H}^{3}$-water in body fluids by liquid scintillation spectrometry. Proc. Soc. exp. Biol. (N. Y.) 1959, 102, 8.

10. Somogyi, M. Notes on sugar determination. J. biol. Chem. 1952, 195, 19.

11. Freinkel, N. Personal communication.

12. Bernstein, I. A., and H. G. Wood. Determination of isotopic carbon patterns in carbohydrate by bacterial fermentataion in Methods in Enzymology, S. P. Colowick and N. O. Kaplan, Eds. New York, Academic Press, 1957, vol. 4, p. 561.

13. Van Slyke, D. D., and J. Folch. Manometric carbon determination. J. biol. Chem. 1940, 136, 509.

14. Wood, H. G., R. Gillespie, R. G. Hansen, W. A. Wood, and H. J. Hardenbrook. Arteriovenous ${ }^{14} \mathrm{CO}_{2}$ differences and the pentose cycle in the cow's udder. Biochem. J. 1959, 73, 694.

15. Hoskin, F. C. G. A source of error in the use of radioactive substrates for metabolic studies. Arch. Biochem. 1960, 87, 151.

16. Muntz, J. A., and R. E. Carroll. A method for converting glucose to fructose. J. biol. Chem. 1960, 235,1258 .

17. Snedecor, G. W. Statistical Methods Applied to Experiments in Agriculture and Biology, 5th ed., Ames, Iowa, Iowa State College Press, 1956, p. 291.

18. Field, J. B., I. Pastan, P. Johnson, and B. Herring. In vitro stimulaton of the hexose monophosphate pathway in thyroid by thyroid stimulating hormone. Biochem. biophys. Res. Commun. 1959, 1, 284.

19. Katz, J., and H. G. Wood. The use of glucose-C ${ }^{14}$ for the evaluaton of the pathways of glucose metabolism. J. biol. Chem. 1960, 235, 2165.

20. Dumont, J. E. Effect in vitro of thyroid-stimulating hormone on the hexose monophosphate pathway in thyroid. Biochim. biophys. Acta (Amst.) 1961, 46, 195.

21. Ball, E. G., D. B. Martin, and O. Cooper. Studies on the metabolism of adipose tissue. I. The effect of insulin on glucose utilization as measured by the manometric determination of carbon dioxide output. J. biol. Chem. 1959, 234, 774.

22. Schussler, G. C., and S. H. Ingbar. The role of intermediary carbohydrate metabolism in regulating organic iodinations in the thyroid gland. J. clin. Invest. 1961, 40, 1394.

23. Dumont, J. E. Hexose monophosphate pathway in thyroid tissue. Biochim. biophys. Acta (Amst.) 1960, 40, 354.

24. Leonards, J. R., and B. R. Landau. A study on the equivalence of metabolic patterns in rat adipose tissue: insulin versus glucose concentration. Arch. Biochem. 1960, 91, 194.

25. Pastan, I., B. Herring, P. Johnson, and J. B. Field. Studies on the mechanism by which epinephrine stimulates glucose oxidation in the thyroid. J. biol. Chem. 1962, 237, 287.

26. Bates, R. W., and P. G. Condliffe. Studies on the chemistry and bioassay of thyrotropins from bovine pituitaries, transplantable pituitary tumors of mice, and blood plasma in Recent Progress in Hormone Research, G. Pincus, Ed. New York Academic Press, 1960, vol. 16, p. 309.

27. Crigler, J. F., Jr. Thyrotropic hormone(s) in Hormones in Human Plasma, 1st ed., H. N. Antoniades, Ed. Boston, Little, Brown, 1960, p. 201.

28. Bakke, J. L., N. Lawrence, F. Arnett, and W. MacFadden. The fractionation of exogenous and endogenous thyroid stimulating hormone from human and rat plasma and tissues. J. clin. Endocr. 1961, $21,1280$.

29. Freinkel, N. Further observations concerning the action of pituitary thyrotropin on the intermediate metabolism of sheep thyroid tissue in vitro. Endocrinology 1960, 66, 851.

30. Williams, H. E., P. Johnson, and J. B. Field. In vitro effects of chorionic gonadotropin on carbohydrate metabolism in rat and bovine corpus luteum (abstract). Clin. Res. 1962, 10, 238.

31. Klainer, L. M., Y.-M. Chi, S. L. Freidberg, T. W. Rall, and E. W. Sutherland. Adenyl cyclase. IV. The effects of neurohormones on the formation of adenosine $3^{\prime}, 5^{\prime}$-phosphate by preparations from brain and other tissues. J. biol. Chem. 1962, 237, 1239. 